\section{Autoregulation of TDP-43 mRNA levels involves interplay between transcription, splicing, and alternative polyA site selection}

\author{
S. Eréndira Avendaño-Vázquez, ${ }^{1,3}$ Ashish Dhir, ${ }^{2,3}$ \\ Sara Bembich, ${ }^{1,3}$ Emanuele Buratti, ${ }^{1}$ \\ Nicholas Proudfoot, ${ }^{2,4}$ and Francisco E. Baralle ${ }^{1,4}$ \\ ${ }^{1}$ International Centre for Genetic Engineering and \\ Biotechnology, 34149 Trieste, Italy; ${ }^{2}$ Sir William Dunn School \\ of Pathology, University of Oxford, Oxford OX1 3RE, United \\ Kingdom
}

TDP-43 is a critical RNA-binding factor associated with pre-mRNA splicing in mammals. Its expression is tightly autoregulated, with loss of this regulation implicated in human neuropathology. We demonstrate that TDP-43 overexpression in humans and mice activates a $3^{\prime}$ untranslated region (UTR) intron, resulting in excision of the proximal polyA site (PAS) $\mathbf{p A}_{1}$. This activates a cryptic PAS that prevents TDP-43 expression through a nuclear retention mechanism. Superimposed on this process, overexpression of TDP-43 blocks recognition of $\mathrm{pA}_{1}$ by competing with CstF-64 for PAS binding. Overall, we uncover complex interplay between transcription, splicing, and 3 ' end processing to effect autoregulation of TDP-43.

Supplemental material is available for this article.

Received April 24, 2012; revised version accepted June 21, 2012.

Genes that encode RNA-binding proteins (RBPs) such as PTB, hnRNP L, and SRSF1 are autoregulated to maintain a constant level of mRNA (Buratti and Baralle 2011). This autoregulatory process may be achieved in part by selective alternative splicing events that trigger nonsensemediated decay (NMD)-mediated RNA degradation (Lejeune and Maquat 2005). The general term RUST (regulated unproductive splicing and translation) has been proposed to describe this category of gene regulation (Lareau et al. 2007a).

However, recently, several studies have highlighted the presence of ultraconserved sequences within selected introns of genes encoding many hnRNP family members. These conserved sequences point to additional autoregulatory mechanisms (Lareau et al. 2007b; Ni et al. 2007;

[Keywords: ALS; FTD; TDP-43; autoregulation; mRNA splicing; polyadenylation]

${ }^{3}$ These authors contributed equally to this work

${ }^{4}$ Corresponding authors

E-mail baralle@icgeb.org

E-mail nicholas.proudfoot@path.ox.ac.uk

Article is online at http://www.genesdev.org/cgi/doi/10.1101/gad.194829.112.

Freely available online through the Genes \& Development Open Access option.
Saltzman et al. 2008). Previously, we reported that the nuclear hnRNP protein TDP-43 maintains its protein levels by binding to and regulating the levels of its own mRNA (Ayala et al. 2011). In particular, we identified a TDP-43-binding region (TDPBR) (Fig. 1A) in the highly conserved 3' untranslated region (UTR) of TDP-43 mRNA and showed that this element is critical for TDP-43 proteostasis. Steady-state analysis of TDP-43 mRNA showed that two different mRNAs of $4.2 \mathrm{~kb}$ and $2.8 \mathrm{~kb}$ are present in the cell in a ratio of $\sim 1: 3$ (Ayala et al. 2011). These mRNA isoforms differ in the length of their 3' UTR, with the 2.8-kb mRNA using a proximal polyA site $\left(\mathrm{PAS} ; \mathrm{pA}_{1}\right)$ and $4.2-\mathrm{kb}$ mRNA using a distal PAS (pA $\left.\mathrm{pA}_{4}\right)$. Other putative PAS usage was not detected (Fig. 1A). A minor variant TDP-43 1.9-kb mRNA was also observed (V2 in Ayala et al. 2011; isoform 3 in Polymenidou et al. 2011). This mRNA is formed by two alternative splicing events in the $3^{\prime}$ UTR that remove both the TDP-43 stop codon and the $\mathrm{pA}_{1}$ PAS. Even though this variant mRNA undergoes NMD, it is not involved in TDP-43 autoregulation (Ayala et al. 2011) in spite of contrary suggestions (Polymenidou et al. 2011). In particular, V2 mRNA levels do not change following TDP-43 overexpression and hence cannot play a significant role in TDP-43 autoregulation. Furthermore, suppression of NMD by translation inhibition (cycloheximide [CHX] treatment) or Upf1 mRNA knockdown failed to increase V2 mRNA amounts to levels detectable by Northern blot analysis (Ayala et al. 2011). Although a possible role for V2 mRNA in TDP-43 autoregulation in other conditions/tissues is not ruled out, this study presents a distinct and unanticipated molecular mechanism for TDP-43 autoregulation. This involves complex interplay between transcription elongation, splicing, and 3 ' end cleavage and polyadenylation.

\section{Results and Discussion}

\section{Cis-acting elements and molecular events in TDP-43 autoregulation}

To identify essential RNA sequences involved in TDP-43 autoregulation, we used a previously described hybrid construct containing a GFP reporter gene fused to the 3' region of TDP-43 (GFP-3'UTR), shown to reproduce the autoregulation observed for endogenous TDP-43. Mutations were engineered into the TDP-43 3' UTR in this construct, and the resulting constructs were transfected into HEK-293 cells also carrying an integrated tetracycline-inducible TDP-43 cDNA (Fig. 1B; Ayala et al. 2011).

We initially confirmed the importance of the previously identified 3' UTR TDPBR. The construct GFP-3'UTR $\triangle$ TDPBR carries a 615-nucleotide (nt) deletion that removes the entire TDPBR, leaving only short intron 7 segments that retain the $5^{\prime}$ and $3^{\prime}$ splice sites. Comparison of the protein expression of the wild-type GFP-3'UTR construct with GFP-3'UTR $\triangle$ TDPBR confirmed the importance of TDPBR for autoregulation. Thus, no GFP down-regulation occurs with the $\triangle$ TDPBR transgene following tetracycline induction of TDP-43 expression (Fig. 1B). In these experiments, GFP protein production was normalized by cotransfection with a plasmid expressing DiGFP (Fig. 1B, DiGFP lanes). A series of further deletions (data not shown) revealed that the minimal 


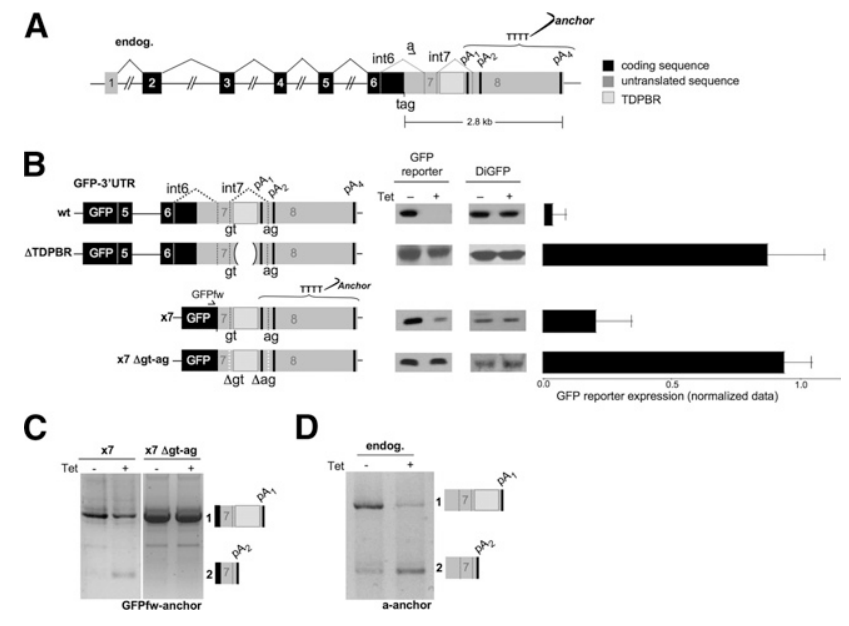

Figure 1. Cis-acting elements and molecular events in TDP-43 autoregulation. (A) Schematic diagram of TDP-43 illustrating locations of the stop codon $(\operatorname{tag})$, PASs $\left(\mathrm{pA}_{1-4}\right)$, the TDPBR, and splicing events (in coding sequences, filled lines; in $3^{\prime}$ UTR, dotted lines). Coding regions (black boxes), untranslated sequences (gray boxes), and introns (connecting black lines) are indicated. RT-PCR primers are indicated. $(B, l e f t)$ Schematic representation of the GFP-3'UTR reporters are shown. (Middle) Western blots of GFP reporter protein in normal (-Tet) and TDP-43 overexpression conditions (+Tet) are shown. (Right) The bar chart shows densitometric quantification of protein expression, normalized against DiGFP expression. Mean values are plotted; error bars indicate the SD from at least three independent experiments. (C) 3' RACE analysis (-Tet and +Tet) for x7 (left) and x7 $\Delta$ gt-ag (right) reporters using the specific GFPfw and anchor primers (see A). (Right) The schematic representation denotes amplified mRNA isoforms (bands 1 and 2) confirmed by sequence analysis. (D) 3' RACE analysis of endogenous TDP-43 (-Tet and +Tet). The forward primer annealed to intron 6 (a), while the anchor was used as the reverse primer (see A). (Right) Amplified mRNA isoforms are indicated.

sequences needed to preserve TDP-43 autoregulation were retained in the construct named $\mathrm{x} 7$ (Fig. 1B), which contains only the TDP-43 $3^{\prime}$ UTR sequence including intron 7 and the intronic $\mathrm{pA}_{1}$. Interestingly, point mutation of intron $75^{\prime}$ and $3^{\prime}$ splice sites in $\mathrm{x} 7$ causes a loss of TDP-43 autoregulation (see below).

TDP-43 autoregulation of wild-type GFP-3'UTR has previously been investigated by Northern blot analysis. However, no new mRNA species were detected following TDP-43 overexpression (Ayala et al. 2011). Suspecting that increased TDP-43 cellular levels may result in the generation of unstable TDP-43 transcripts, we analyzed GFP-TDP-43 transcripts by 3' RACE analysis using primers specific for the GFP reporter sequence (Fig. 1C). As shown for the $\mathrm{x} 7$ (-Tet) lane, a single product was obtained (band 1) containing a TDP-43 3' UTR sequence ending at $\mathrm{pA}_{1}$. Upon induction $(+\mathrm{Tet})$, the $\mathrm{x} 7$ band 1 diminished and a new product appeared (band 2), which, based on sequencing, derives from the TDP-43 3' UTR ending at a cryptic PAS, $\mathrm{pA}_{2}$. Quantification of this PAS switch was shown to be reproducibly fivefold (Supplemental Fig. 1). The formation of band 2 is caused by the activation of intron 7 splicing, which in turn eliminates PAS $\mathrm{pA}_{1}$ as well as the entire TDPBR. These results suggest that splicing of intron 7 is a critical event for TDP-43 autoregulation. To test this possibility, we mutated the splice sites flanking intron 7 to obtain the construct $x 7 \Delta$ gt-ag (Fig. 1B). Following transfection of $x 7 \Delta$ gt-ag into the HEK293 cell line with or without Tet activation of TDP-43 expression, we observed that the lack of intron 7 splice sites prevents the autoregulation seen with $\mathrm{x} 7$ (Fig. 1B). Thus, only band 1 is detectible in both - Tet and +Tet lanes (Fig. 1C, right panel). Overall, these initial results suggest that TDP-43 overexpression may act to enhance intron 7 splicing, thereby preventing recognition of the intronic $\mathrm{pA}_{1}$ PAS and in turn causing a switch in PAS usage to $\mathrm{pA}_{2}$.

\section{Switch in splicing patterns and PAS usage on the endogenous gene following TDP-43 overexpression}

We next tested whether the above GFP-3'UTR construct autoregulation by TDP-43 overexpression mirrors regulation of endogenous TDP-43. 3' RACE analysis of the endogenous TDP-43 transcripts showed that TDP-43 overexpression switches the profile from an intron 7-containing RNA that uses $\mathrm{pA}_{1}$ (band 1) to the smaller band 2 product that lacks intron 7 and so uses the $\mathrm{pA}_{2}$ PAS. In effect, endogenous TDP-43 and $\mathrm{x} 7$ reporter constructs reproducibly give similar PAS switching when TDP-43 is overexpressed (Supplemental Fig. 1). It should be emphasized that for endogenous TDP-43, only two mRNAs are readily detectible by Northern blotting. The larger $4.2-\mathrm{kb}$ mRNA retains introns 6 and 7 and uses the $\mathrm{pA}_{4}$ PAS, while the smaller 2.8-kb mRNA uses the intron $7 \mathrm{pA}_{1}$ PAS (Ayala et al. 2011). Transcripts containing just intron 6 (i.e., band 2 with intron 7 spliced) are only detected at a low level by 3 ' RACE and, in this case, use the $\mathrm{pA}_{2}$ PAS. Finally, transcripts containing only intron 7 (with intron 6 spliced) are undetectable even by RT-PCR (data not shown).

Our analysis of TDP-43 transcripts as above (Fig. 1) used total cellular RNA. However, we wished to test whether specific TDP-43 transcripts display a nuclear retention pattern. We therefore performed 3' RACE on endogenous TDP-43 mRNA using separate nuclear and cytoplasmic RNA fractions isolated from cells with or without Tet induction of TDP-43 expression (Fig. 2A). While band 1 was detectable in both nuclear and cytoplasmic fractions, the autoregulation-associated band 2 was predominantly nuclear and therefore not available for translation (Fig. $2 \mathrm{~A}$, left panel, cf. the intensity of band 2 between the -Tet and +Tet conditions). These results neatly explain the rapid disappearance of the endogenous protein. This nuclear retention result provides the first indication that this form of TDP-43 autoregulation is different from NMD-associated autoregulation as shown for the minor V2 TDP-43 mRNA isoform (described above). In particular, we also show that translation inhibition by CHX treatment (Fig. 2A, CHX panel, primers a and anchor) does not affect the levels of the band 2 RNA that uses $\mathrm{pA}_{2}$. Finally, to prove that NMD was efficiently blocked in this experiment, we performed a PCR analysis on the same samples using primers that detected the V2 form in which both introns 6 and 7 are spliced (Fig. 2A, right panel, primers b and c). In this experiment, it is clear that the V2 mRNA undergoes $\mathrm{NMD}$, as V2 levels increase upon CHX treatment. Importantly, V2 mRNA levels are unchanged following Tet induction of TDP-43. We conclude that V2 mRNA is not involved in TDP-43 autoregulation, as its expression does not change in response to the TDP-43 overexpression even when the NMD mechanism is blocked by CHX treatment or following Upf1 knockdown (Ayala et al. 2011). Finally, with regard to the endogenous TDP-43, we note that use of the $\mathrm{pA}_{4}$ site followed a nuclear versus cytoplasmic bias similar to that observed above for $\mathrm{pA}_{2}$. However, with this PAS, no RT-PCR product was detected (Fig. 2) because of the excessive distance between this site and the forward 
A

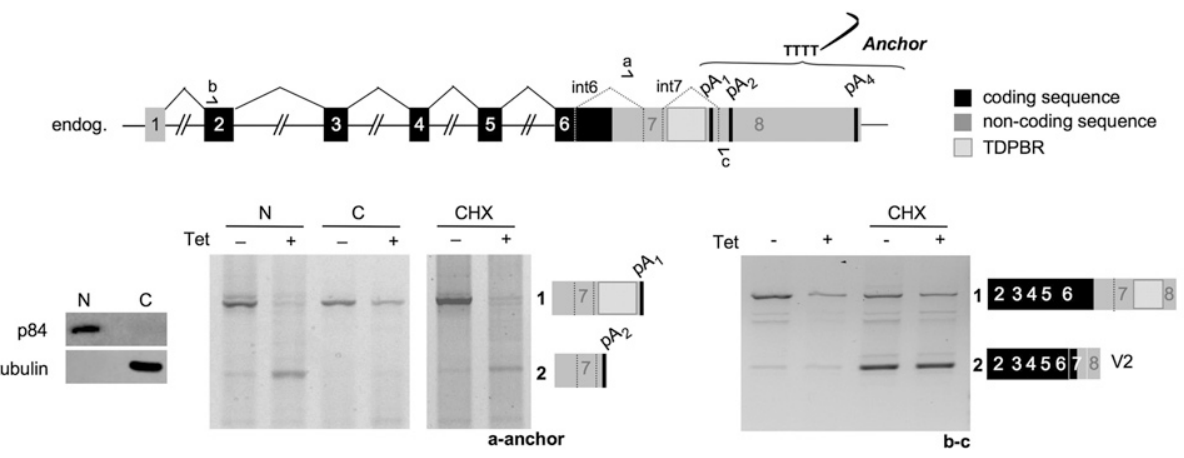

B

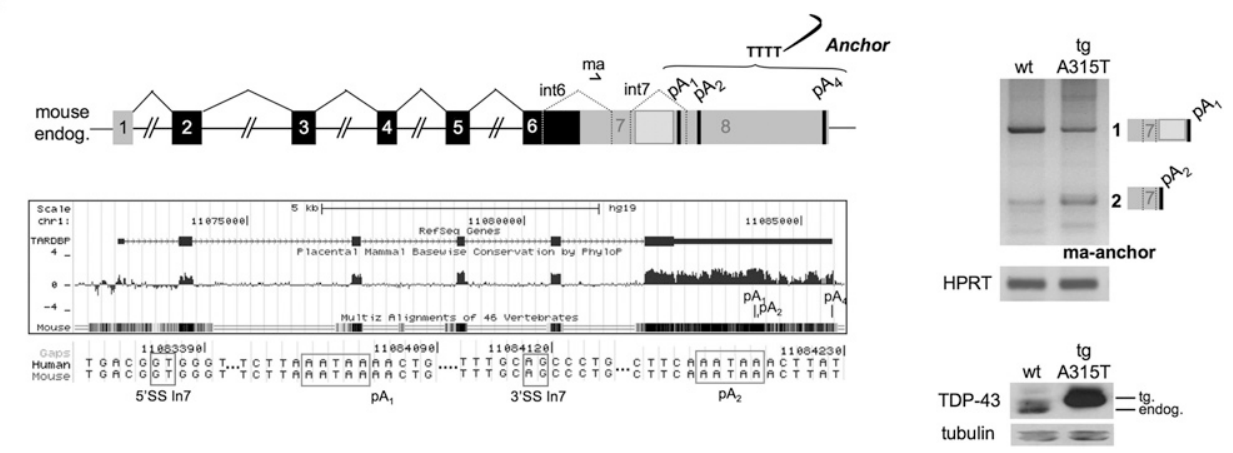

Figure 2. Endogenous TDP-43 in mice and humans; mRNA intron 7 splicing, PAS usage, and mRNAs nuclear retention. (A) Schematic representation of human TDP-43. Arrows show the positions of the primers used. $3^{\prime}$ RACE analysis of endogenous TDP-43 before (-Tet) and following (+Tet) TDP-43 transgene induction performed on nuclear (N) and cytoplasmic (C) RNA fractions or following CHX treatment. The forward primer was annealed to intron 6 (a), while the anchor was used as the reverse primer. (Right) The same samples were checked for the amplification of the endogenous variant V2 mRNA using primers b and c as indicated. All PCR products were sequenced to establish their identity. Distribution of p84 and tubulin was analyzed by Western blotting. ( $B$, left) Schematic diagram of mouse TDP-43 showing sequence conservation between humans and mice and detailed alignment of the sequence corresponding to intron 7 splice sites and the various PAS. (Right) 3' RACE analysis of endogenous murine TDP-43 from control (wild-type [wt]) and transgenic tg A315T mouse brains. The forward primer is annealed on intron 6 (named ma), while the anchor was used as the reverse primer. A representation of amplified mRNA isoforms (bands 1 and 2) is also shown as confirmed by sequencing. HPRT mRNA amplification was used as a control. (Bottom right) Endogenous and transgenic tg A315T protein expression was measured by Western blotting using anti-TDP-43, with anti-tubulin as control.

primer. A nuclear retention bias for mRNA using $\mathrm{pA}_{4}$, however, was shown by RT-qPCR analysis using primers that span the $\mathrm{pA}_{4}$ region (Supplemental Fig. 2).

\section{Intron 7 splicing and PAS usage in a murine TDP-43 overexpression model}

To validate the results obtained in our HEK-293 cell line, we took advantage of a murine TDP-43 transgenic mouse model that overexpresses a mutant form (TDP-43 ${ }^{\mathrm{A} 315 \mathrm{~T}}$ ) of the protein (Wegorzewska et al. 2009). TDP-43 autoregulation was shown to occur in this transgenic mouse, as overexpression of the human transgene down-regulates the endogenous mouse TDP-43 protein (Wegorzewska et al. 2009). Strikingly, murine TDP-43 conserves a gene structure over the $3^{\prime}$ UTR closely similar to its human counterpart, including intron 7-containing $\mathrm{pA}_{1}$ as well as the close downstream pA2 PAS (Fig. 2B). We therefore performed 3' RACE analysis on murine TDP-43 and observed identical autoregulation of PAS choice between the human and mouse systems, as predicted from the close homology between their 3' UTR sequences (Fig. 2B, left panels). In particular, intron $73^{\prime} \mathrm{RACE}$ analysis of endogenous brain TDP-43 transcripts from control (wildtype) and transgenic TDP-43 ${ }^{\mathrm{A} 315 \mathrm{~T}}(\operatorname{tg} \mathrm{A} 315 \mathrm{~T})$ mice using a specific intron 6 forward primer (ma) was performed together with HPRT as a housekeeping gene control. Analysis of control littermates was compared with the transgenic line that overexpresses TDP-43 and showed an effect that closely resembled the $\mathrm{pA}_{1}$-to- $\mathrm{pA}_{2}$ switch observed in the human HEK-293 cell lines, including the processing of intron 7 in a significant amount of total transcript (Fig. 2B, top right panels). Taken together, these results show that the autoregulatory process that mediates PAS switching in human TDP-43 is conserved in mice.

\section{RNA polymerase II (Pol II) density through the TDPBR in the TDP-43 gene 3' UTR}

We sought to better understand how TDP-43 overexpression acts to promote intron 7 splicing, resulting in the formation of a nuclear-retained transcript that uses $\mathrm{pA}_{2}$. It is well established that RNA processing, both splicing and cleavage/polyadenylation, occurs cotranscriptionally and that transcription kinetics can directly affect RNA processing specificity (Kornblihtt 2007; Moore and Proudfoot 2009). We therefore considered the possibility that TDP-43 levels might directly or indirectly affect TDP-43 transcription. The profile of nascent RNA and Pol II density over TDP-43 was therefore assessed under both normal conditions and following Tet-induced TDP43 transgene overexpression. 
As a first approach, Br-UTP run-on assays were performed across TDP-43 from the promoter to $500 \mathrm{nt}$ beyond the 3' UTR using different probes (Fig. 3A). This technique allows detection of nascent transcription by the isolation and RT-PCR analysis of BrU-labeled RNA synthesized during the run-on reaction. Figure 3B shows a high run-on signal over the promoter region $(\mathrm{X} 1)$ that then drops to lower levels in the gene body (X4int4), indicative of promoter-proximal pausing as generally observed for protein-coding genes (Guenther et al. 2007). Strikingly higher run-on signals were again observed over the TDPBR (X6c signal) and, to a lesser extent, in the downstream regions of the gene $\left(\mathrm{pA}_{1}\right.$, $\mathrm{h} 2 \mathrm{pA}_{4}$, and $3^{\prime} \mathrm{pA}_{4}$ signal). Overexpression of TDP-43 accentuated this asymmetric nascent RNA profile with even higher levels of nascent RNA detectible over the TDPBR. This correlates with the capacity of TDP-43 to bind the TDPBR as previously shown (Ayala et al. 2011) and confirmed the more recent cross-linking immunoprecipitation (CLIP) studies (Polymenidou et al. 2011; Tollervey et al. 2011). Furthermore, these results suggest that overexpression of TDP-43 causes additional Pol II stalling that could induce the more efficient recognition and splicing of intron 7 (Kornblihtt 2007), with the consequent removal of the $\mathrm{pA}_{1}$. Our results also show that TDP-43 overexpression promotes an increase in nascent RNA over the region downstream from $\mathrm{pA}_{1}$ and beyond $\mathrm{pA}_{4}$. This increased level of TDP-43 nascent RNA may reflect transcripts that fail to complete RNA maturation steps. This could further contribute to transcript degradation and hence to the autoregulation mechanism. To confirm that higher nascent RNA levels over the TDPBR are due to Pol II stalling, we next carried out chromatin immunoprecipitation (ChIP) analysis using an antibody against the $\mathrm{N}$ terminus of the largest Pol II subunit (N20) (Fig. 3C) and the H5 antibody that specifically recognizes Pol II C-terminal domain (CTD) repeats phosphorylated at Ser 2 (Fig. 3D). The profiles obtained for these experiments were similar to the BrUTP run-on analysis, confirming that TDP-43 overexpression promotes an elongation/termination defect as indicated

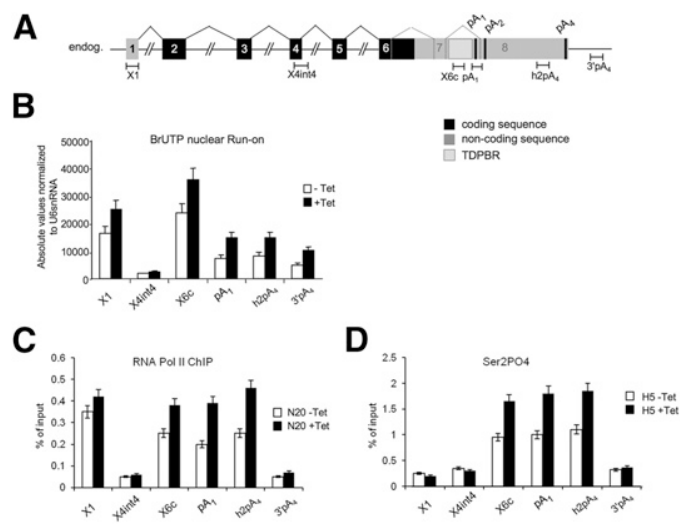

Figure 3. Pol II stalling on the TDPBR sequence. (A) Schematic diagram of TDP-43 showing positions of ChIP probes used. $(B) \mathrm{BrU}$ nuclear run-on assay measuring nascent transcription in different regions of endogenous TDP-43 under normal conditions (-Tet) and following TDP-43 overexpression (+Tet). (C,D) ChIP analysis using N20 Pol II and H5 Pol II CTDser2P antibodies probing the same regions of $T D P-43$. by increased Pol II signals extending from the TDPBR to $3^{\prime}$ of $\mathrm{pA}_{4}$.

\section{TDP-43 overexpression blocks recognition of $p A_{1}$ by CstF-64}

We also considered the possibility that TDP-43 overexpression might directly affect TDP-43 PAS selection and, in particular, could act by blocking $\mathrm{pA}_{1}$ usage. This would in turn promote intron 7 splicing. In particular, the GU-rich RNA recognition specificity for TDP-43 (Buratti and Baralle 2001) is remarkably similar to the binding specificity of the key cleavage polyA factor CstF-64, which is represented by $\mathrm{GU}_{3-5}-\mathrm{U}_{2-4}$ (Takagaki and Manley 1997). Indeed, the $\mathrm{pA}_{1}$-surrounding sequence possesses a clear GU-rich downstream sequence element (DSE) that is known to provide for efficient CstF-64 recruitment. Furthermore, CLIP analysis of TDP-43 to the TDPBR shows that binding extends through to $\mathrm{pA}_{1}$, with a peak of interaction lying directly over the PAS DSE (Fig. 4A). We therefore performed RNA immunoprecipitation (RIP) analysis using TDP-43- and CstF-64-specific antibodies with or without TDP-43 overexpression. The selected RNA was subjected to quantitative RT-PCR (RT-qPCR) with primers directly encompassing $\mathrm{pA}_{1}$. As a control, the major PAS of HPRT1 (HPRT pA) that has no welldefined DSEs in its sequence was similarly tested using specific primers with the same RNA samples. For endogenous TDP-43, CstF-64 antibody yielded a clear RIP signal for $\mathrm{pA}_{1}$ under normal conditions that was reduced fourfold following TDP-43 overexpression (Fig. 4B, top graph). In a reciprocal manner, TDP-43 antibody immunoprecipitated twofold more $\mathrm{pA}_{1}$ RNA when overexpressed (Fig. 4B, bottom graph). In contrast, control probes against HPRT1 pA showed little TDP-43 RIP signal whether induced or not, while CstF-64 signal remained unchanged between induced and uninduced samples (Fig. 4C, top and bottom graphs). Taken together, these results establish that TDP-43 overexpression specifically outcompetes CstF-64 binding to the $\mathrm{pA}_{1}$ DSE during TDP-43 transcription.

The interconnections between alternative splicing and polyadenylation represent an important level of regulation (Lutz and Moreira 2011; Proudfoot 2011). In recent years, the splicing process has been shown to affect polyadenylation through the recognition of a gene's terminal intron 3' splice site (Dye and Proudfoot 1999), "licensing" release of polyadenylated mRNA from Pol II (Rigo and Martinson 2009), and protecting pre-mRNAs from premature cleavage and polyadenylation through the U1snRNP molecule pathway (Kaida et al. 2010). The autoregulation process for TDP-43 expression defined in this study shows some parallels with regulated PAS selection for immunoglobulin heavy chain (IgH) mRNA (Takagaki and Manley 1998) and the the HuR protein (Dai et al. 2012). However, there are fundamental differences between TDP-43 autoregulation and these genes. In neither the IgH nor HuR system is the splicing process coupled closely to CstF-64 competition. Our data point to a combined mechanism of TDP-43 autoregulation where each component of the coupled transcription RNA processing mechanism, transcriptional stalling, consequent splicing activation, and CstF64 displacement, plays a combined role in modulating PAS selection. We therefore propose a novel autoregulation model for TDP-43 (Fig. 5). In this model, increased nuclear levels of TDP-43 result in increased TDPBR occupancy. The higher density of 
A

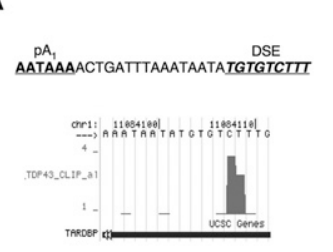

B
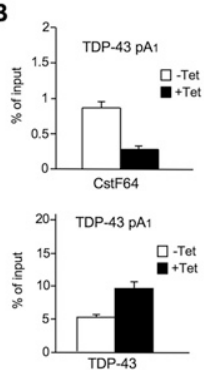

C
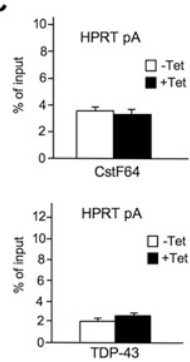

Figure 4. Competition between TDP-43 and CstF-64 across the $\mathrm{pA}_{1}$ site. (A) Nucleotide sequence of TDP-43 pA 1 DSE $(t o p)$ and a hit frequency plot of TDP-43 CLIP data (bottom) (from the University of California at Santa Cruz Genome Browser). (B) RIP analysis of TDP-43 and CstF-64 proteins on endogenous TDP-43 across $\mathrm{pA}_{1}$ under normal $(-\mathrm{Tet})$ and TDP-43 overexpression (+Tet) conditions. (C) RIP for TDP-43 and CstF-64 proteins across the HPRT PAS used as control.

TDP-43 in this region, which also extends into the DSE of $\mathrm{pA}_{1}$, elicits a "slowdown" of Pol II over intron 7 coinciding with both the $\mathrm{pA}_{1}$ PAS and intron $73^{\prime}$ splice site. Since Pol II pausing is known to favor recognition of suboptimal splice sites by the spliceosomal complex (Kornblihtt 2007), removal of intron 7 including $\mathrm{pA}_{1}$ is enhanced, thus enforcing $\mathrm{pA}_{2}$ selection. In addition, TDP-43 binding to intron 7 may facilitate its removal by favoring a particular conformation of the intronic sequence and/or by recruiting other splicing factors to this region. Pre-mRNA molecules that do not undergo intron 7 splicing continue their synthesis toward the $\mathrm{pA}_{4}$ PAS or beyond. However, in this situation, the processing at $\mathrm{pA}_{1}$ is hampered by TDP-43 binding that reduces CstF-64 interaction with its target sequence in the $\mathrm{pA}_{1}$ site. As both $\mathrm{pA}_{2}$ and the distal PAS $\left(\mathrm{pA}_{4}\right)$ are significantly retained in the nucleus and rapidly degraded, it follows that a reduction of TDP-43 protein levels in the cell will occur.

In conclusion, TDP-43 autoregulation represents an alternative to regulatory mechanisms based on classical NMD pathways. This may explain some of the processes that lead to TDP-43 aggregation and consequent neuronal death in neurodegenerative diseases. Since aberrant TDP-43 levels result in cytoplasmic/nuclear aggregation, this may act as a TDP-43 "sink" that promotes the setup of a vicious cycle of ever-increasing TDP-43 production that in the long run will be harmful to cellular metabolism. Indeed, there is already evidence that deregulation of TDP-43 protein levels occurs in patient samples. Thus, several studies report an increase of TDP-43 mRNA levels in the brains of patients affected by various forms of frontotemporal lobar degeneration (FTLD) (Mishra et al. 2007; Chen-Plotkin et al. 2008; Kabashi et al. 2008; Weihl et al. 2008). Moreover, we know from several recent animal models and adeno-associated virus (AAV) overexpression systems that raising TDP-43 concentrations can lead to neurodegeneration (Tatom et al. 2009; Barmada et al. 2010; Li et al. 2010; Liachko et al. 2010; Wils et al. 2010; Xu et al. 2010; Wegorzewska and Baloh 2011). We predict that a deeper understanding of the mechanisms that control production of TDP-43 within the cell may lead to the development of improved therapeutic approaches for these pathologies.

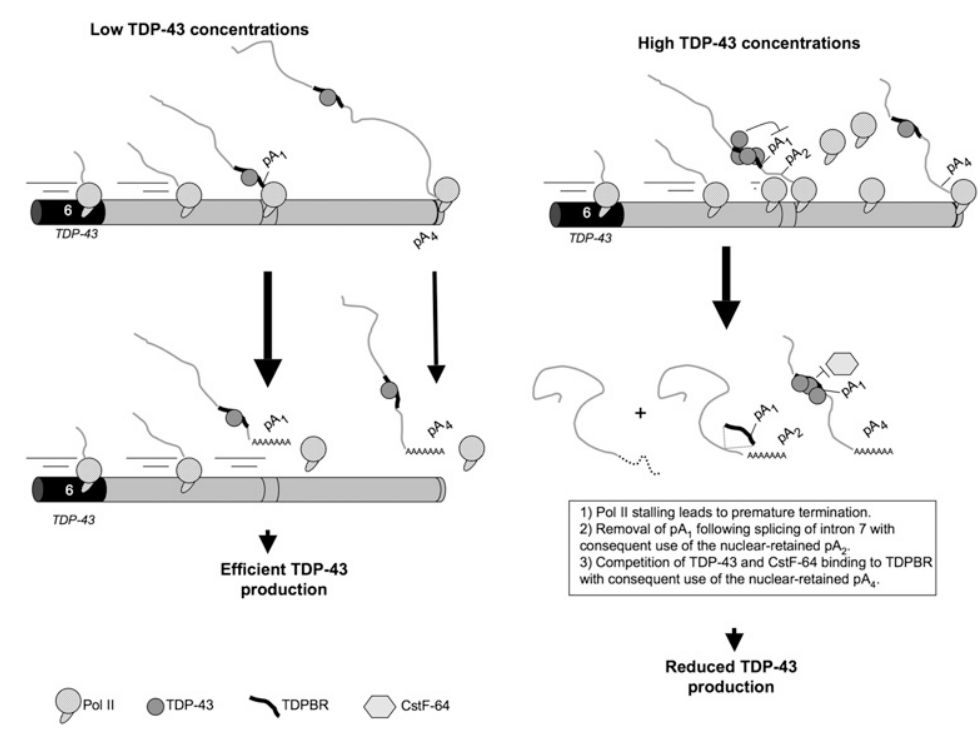

Figure 5. Model of TDP-43 autoregulatory mechanism. Under normal conditions, Pol II synthesizes the nascent TDP-43 mRNA from TDP-43, generating two main TDP-43 mRNA isoforms using either $\mathrm{pA}_{1}$ or $\mathrm{pA}_{4}$, which results in efficient TDP-43 protein expression. When the levels of nuclear TDP-43 rise, there is an increase in the binding of TDP-43 to the TDPBR. This promotes a dual effect: increased intron 7 splicing with the physical removal of the $\mathrm{pA}_{1}$ signal, and direct competition with the cleavage polyA factor Cstf-64 over $\mathrm{pA}_{1}$. Moreover, Pol II stalling may lead to premature termination of transcription and rapid degradation. 


\section{TDP-43 CstF-64 competition and statistical analysis}

RNA fractions isolated from cells with or without TDP-43 overexpression were immunoprecipitated using TDP-43- or CstF-64-specific antibodies. As control, the major PAS of the HPRT gene was similarly tested using specific primers with the same RNA samples (sequence available on request). Significant differences $(P<0.05)$ in GFP protein expression values were determined using ANOVA with a Newman-Keuls post-test.

\section{Acknowledgments}

We thank Patrizia Longone and Michele Nutini (Fondazione Santa Lucia, Rome) for their gift of A315T mouse brains, Jernej Ule for the TDP-43 CLIP files, and Somdutta Dhir for bioinformatics analyses. This work was supported by AriSLA. A.D. is supported by an EMBO long-term fellowship. A.D. and N.J.P. are supported by a Programme Grant from the Wellcome Trust.

\section{References}

Ayala YM, Zago P, D'Ambrogio A, Xu YF, Petrucelli L, Buratti E, Baralle FE. 2008. Structural determinants of the cellular localization and shuttling of TDP-43. J Cell Sci 121: 3778-3785.

Ayala YM, De Conti L, Avendano-Vazquez SE, Dhir A, Romano M, D'Ambrogio A, Tollervey J, Ule J, Baralle M, Buratti E, et al. 2011. TDP-43 regulates its mRNA levels through a negative feedback loop. EMBO J 30: 277-288.

Barmada SJ, Skibinski G, Korb E, Rao EJ, Wu JY, Finkbeiner S. 2010. Cytoplasmic mislocalization of TDP-43 is toxic to neurons and enhanced by a mutation associated with familial amyotrophic lateral sclerosis. J Neurosci 30: 639-649.

Buratti E, Baralle FE. 2001. Characterization and functional implications of the RNA binding properties of nuclear factor TDP-43, a novel splicing regulator of CFTR exon 9. J Biol Chem 276: 36337-36343.

Buratti E, Baralle FE. 2011. TDP-43: New aspects of autoregulation mechanisms in RNA binding proteins and their connection with human disease. FEBS J 278: 3530-3538.

Chen-Plotkin AS, Geser F, Plotkin JB, Clark CM, Kwong LK, Yuan W, Grossman M, Van Deerlin VM, Trojanowski JQ, Lee VM. 2008. Variations in the progranulin gene affect global gene expression in frontotemporal lobar degeneration. Hum Mol Genet 17: 1349-1362.

Dai W, Zhang G, Makeyev EV. 2012. RNA-binding protein HuR autoregulates its expression by promoting alternative polyadenylation site usage. Nucleic Acids Res 40: 787-800.

Dye MJ, Proudfoot NJ. 1999. Terminal exon definition occurs cotranscriptionally and promotes termination of RNA polymerase II. Mol Cell 3: 371-378.

Guenther MG, Levine SS, Boyer LA, Jaenisch R, Young RA. 2007. A chromatin landmark and transcription initiation at most promoters in human cells. Cell 130: 77-88.

Kabashi E, Valdmanis PN, Dion P, Spiegelman D, McConkey BJ, Vande Velde C, Bouchard JP, Lacomblez L, Pochigaeva K, Salachas F, et al. 2008. TARDBP mutations in individuals with sporadic and familial amyotrophic lateral sclerosis. Nat Genet 40: 572-574.

Kaida D, Berg MG, Younis I, Kasim M, Singh LN, Wan L, Dreyfuss G. 2010. U1 snRNP protects pre-mRNAs from premature cleavage and polyadenylation. Nature 468: 664-668.

Kornblihtt AR. 2007. Coupling transcription and alternative splicing. Adv Exp Med Biol 623: 175-189.

Lareau LF, Brooks AN, Soergel DA, Meng Q, Brenner SE. 2007a. The coupling of alternative splicing and nonsense-mediated mRNA decay. Adv Exp Med Biol 623: 190-211.

Lareau LF, Inada M, Green RE, Wengrod JC, Brenner SE. 2007b. Unproductive splicing of SR genes associated with highly conserved and ultraconserved DNA elements. Nature 446: 926-929.

Lejeune F, Maquat LE. 2005. Mechanistic links between nonsensemediated mRNA decay and pre-mRNA splicing in mammalian cells. Curr Opin Cell Biol 17: 309-315.

Li Y, Ray P, Rao EJ, Shi C, Guo W, Chen X, Woodruff EA III, Fushimi K, Wu JY. 2010. A Drosophila model for TDP-43 proteinopathy. Proc Natl Acad Sci 107: 3169-3174.

Liachko NF, Guthrie CR, Kraemer BC. 2010. Phosphorylation promotes neurotoxicity in a Caenorhabditis elegans model of TDP-43 proteinopathy. J Neurosci 30: 16208-16219.
Lutz CS, Moreira A. 2011. Alternative mRNA polyadenylation in eukaryotes: An effective regulator of gene expression. WIRES RNA 2: 22-31.

Mishra M, Paunesku T, Woloschak GE, Siddique T, Zhu LJ, Lin S, Greco K, Bigio EH. 2007. Gene expression analysis of frontotemporal lobar degeneration of the motor neuron disease type with ubiquitinated inclusions. Acta Neuropathol 114: 81-94.

Moore MJ, Proudfoot NJ. 2009. Pre-mRNA processing reaches back to transcription and ahead to translation. Cell 136: 688-700.

Ni JZ, Grate L, Donohue JP, Preston C, Nobida N, O'Brien G, Shiue L, Clark TA, Blume JE, Ares M Jr. 2007. Ultraconserved elements are associated with homeostatic control of splicing regulators by alternative splicing and nonsense-mediated decay. Genes Dev 21: 708-718.

Polymenidou M, Lagier-Tourenne C, Hutt KR, Huelga SC, Moran J, Liang TY, Ling SC, Sun E, Wancewicz E, Mazur C, et al. 2011. Long pre-mRNA depletion and RNA missplicing contribute to neuronal vulnerability from loss of TDP-43. Nat Neurosci 14: 459-468.

Proudfoot NJ. 2011. Ending the message: Poly(A) signals then and now. Genes Dev 25: 1770-1782.

Rigo F, Martinson HG. 2009. Polyadenylation releases mRNA from RNA polymerase II in a process that is licensed by splicing. RNA 15: 823-836.

Saltzman AL, Kim YK, Pan Q, Fagnani MM, Maquat LE, Blencowe BJ. 2008. Regulation of multiple core spliceosomal proteins by alternative splicing-coupled nonsense-mediated mRNA decay. Mol Cell Biol 28: $4320-4330$.

Skourti-Stathaki K, Proudfoot NJ, Gromak N. 2011. Human senataxin resolves RNA/DNA hybrids formed at transcriptional pause sites to promote Xrn2-dependent termination. Mol Cell 42: 794-805.

Takagaki Y, Manley JL. 1997. RNA recognition by the human polyadenylation factor CstF. Mol Cell Biol 17: 3907-3914.

Takagaki Y, Manley JL. 1998. Levels of polyadenylation factor CstF-64 control IgM heavy chain mRNA accumulation and other events associated with B cell differentiation. Mol Cell 2: 761-771.

Tatom JB, Wang DB, Dayton RD, Skalli O, Hutton ML, Dickson DW, Klein RL. 2009. Mimicking aspects of frontotemporal lobar degeneration and Lou Gehrig's disease in rats via TDP-43 overexpression. Mol Ther 17: 607-613.

Tollervey JR, Curk T, Rogelj B, Briese M, Cereda M, Kayikci M, Konig J, Hortobagyi T, Nishimura AL, Zupunski V, et al. 2011. Characterizing the RNA targets and position-dependent splicing regulation by TDP43. Nat Neurosci 14: 452-458.

Wegorzewska I, Baloh RH. 2011. TDP-43-based animal models of neurodegeneration: New insights into ALS pathology and pathophysiology. Neurodegener Dis 8: 262-274.

Wegorzewska I, Bell S, Cairns NJ, Miller TM, Baloh RH. 2009. TDP-43 mutant transgenic mice develop features of ALS and frontotemporal lobar degeneration. Proc Natl Acad Sci 106: 18809-18814.

Weihl CC, Temiz P, Miller SE, Watts G, Smith C, Forman M, Hanson PI, Kimonis V, Pestronk A. 2008. TDP-43 accumulation in inclusion body myopathy muscle suggests a common pathogenic mechanism with frontotemporal dementia. I Neurol Neurosurg Psychiatr 79: $1186-1189$.

Wils H, Kleinberger G, Janssens J, Pereson S, Joris G, Cuijt I, Smits V, Ceuterick-de Groote C, Van Broeckhoven C, Kumar-Singh S. 2010. TDP-43 transgenic mice develop spastic paralysis and neuronal inclusions characteristic of ALS and frontotemporal lobar degeneration. Proc Natl Acad Sci 107: 3858-3863.

Xu YF, Gendron TF, Zhang YJ, Lin WL, D'Alton S, Sheng H, Casey MC, Tong J, Knight I, Yu X, et al. 2010. Wild-type human TDP-43 expression causes TDP-43 phosphorylation, mitochondrial aggregation, motor deficits, and early mortality in transgenic mice. I Neurosci 30: 10851-10859. 


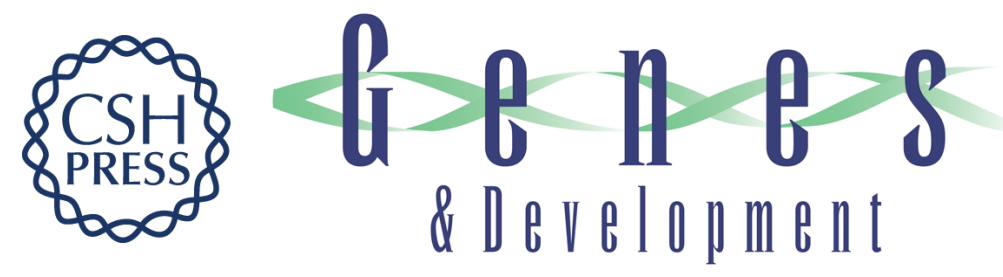

\section{Autoregulation of TDP-43 mRNA levels involves interplay between transcription, splicing, and alternative polyA site selection}

S. Eréndira Avendaño-Vázquez, Ashish Dhir, Sara Bembich, et al.

Genes Dev. 2012, 26:

Access the most recent version at doi:10.1101/gad.194829.112

Supplemental
Material http://genesdev.cshlp.org/content/suppl/2012/08/01/26.15.1679.DC1

References This article cites 35 articles, 14 of which can be accessed free at: http://genesdev.cshlp.org/content/26/15/1679.full.html\#ref-list-1

License Freely available online through the Genes \& Development Open Access option.

Email Alerting Receive free email alerts when new articles cite this article - sign up in the box at the top

Service right corner of the article or click here.

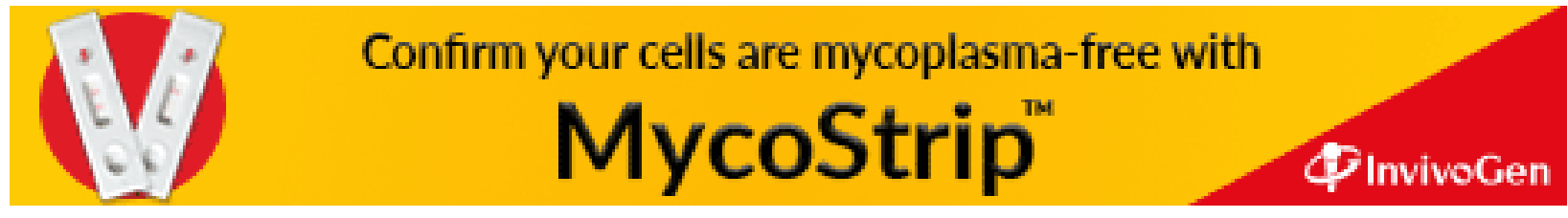

